\title{
PERSPECTIVAS DA HISTÓRIA ECONÔMICA GLOBAL DA BAIXA IDADE MÉDIA
}

Perspectives of Global Economic History in the Late Middle Ages 


\title{
RESUMO
}

Este artigo tem como objetivo apresentar as linhas gerais de um modelo teórico capaz de conduzir uma abordagem econômica da Baixa Idade Média a partir de uma perspectiva global. Para tanto, começaremos reconhecendo as dificuldades inerentes a esse desafio. Na primeira seção, passaremos em revista diferentes estratégias adotadas pela historiografia diante do desafio de conduzir uma investigação utilizando, como unidade de observação geográfica, a macroescala. Na segunda seção, apresentaremos brevemente algumas propostas de História Global, chegando a uma situação historiográfica radicada na oposição de dois modelos constrangedores para o pesquisador em História Medieval: uma teoria que vê o início de relações globais apenas a partir do século XVI, e uma teoria que identifica relações globais a partir da Revolução Neolítica, concedendo pequena importância, quando não um juízo desfavorável, ao período medieval. Na terceira seção, a partir da análise dos fluxos comerciais existentes entre o mar Negro, a Itália e o noroeste da Europa durante o século XIV, teremos oportunidade de elencar algumas características do comércio transcontinental do período. Terminaremos com uma breve reflexão sobre a possibilidade de construir um modelo teórico capaz de investigar o emaranhado de conexões econômicas de longo alcance geográfico que existiam em um mundo essencialmente fragmentado, evitando teoremas gerais abstratos em favor da observação das singularidades locais.

\section{PALAVRAS-CHAVE}

História Econômica Medieval. Sistema-Mundo. História Global.

\begin{abstract}
This article aims to present the general lines of a theoretical model capable of conducting an economic approach of the Late Middle Ages from a global perspective. So to, we will start by analyzing the difficulties inherent to this project. In the first section, we review different strategies adopted by the best historiography considering the challenge of conducting an investigation using Macro Scale as a geographic unit of observation. In the second section, we will briefly present some proposals from the Global History, presenting a historiographical situation rooted in the opposition of two embarrassing models for the researcher in Medieval History: a theory that sees the beginning of global relations in the $16^{\text {th }}$ century, and a theory that identifies global relations in the Neolithic Revolution, granting small importance, when not an unfavorable judgment, for the medieval period. In the third section, from the analysis of the existing trade flows between the Black Sea, Italy and northwest Europe, during the $14^{\text {th }}$ century, we will have the opportunity to clarify some features of the transcontinental trade in the period. Finally, we will end with a brief reflection about the possibility of building a theoretical model capable of investigating the long-distance economic connections that existed in an essentially fragmented world, avoiding abstract general theorems in favor of the observation of local singularities.
\end{abstract}

\section{KEYWORDS}

Medieval Economic History. World-System. Global History. 
“A s Tentações de Santo Antão", tríptico realizado por Hieronymus Bosch, apresenta uma complexidade tão numerosa de elementos pictóricos que dificilmente não causará, na primeira tentativa de observação, um efeito desorientador. Como primeira etapa do processo de compreensão, Wihelm Fraenger (2007) realiza a descrição analítica seccionando o tríptico em diversas "microzonas" narrativas; apenas a asa esquerda é observada a partir de quatro espaços diferentes (o céu, a procissão dos feiticeiros, Santo Antão sobre a ponte socorrido por monges, e a zona infernal do córrego). Nessa primeira etapa, cada "microzona" narrativa guarda pouca ligação com as demais (o incêndio, na zona superior da pintura central, não afeta o festim na parte inferior da asa direita), e exige uma observação particular (constatar o incêndio não auxilia na compreensão das três figuras que compõem o festim) (FRAENGER, 2007). A impressão inicial de uma narrativa constituída de elementos desconexos e desconectados não é rejeitada, mas sim absorvida e subsumida pelo instrumental teórico do investigador. Não obstante, as pinturas compõem uma totalidade, manifesta na moldura do tríptico; e a própria presença de Santo Antão, em diversas cenas, funciona como uma espécie de espinha dorsal que unifica a narrativa repleta de eventos, mensagens e significados conectados e interdependentes (a ligação do festim com o incêndio). O processo de compreensão da totalidade coerente do quadro, nessa metodologia, surge como etapa final de interpretação do tríptico de Bosch. Acaso essa metodologia tem algo a ensinar aos investigadores em História Econômica interessados em uma abordagem global? É possível observar a multidão fragmentada e desorientadora (às vezes infernal) das fontes primárias à procura de um Santo Antão capaz de tornar visível qualquer articulação entre elementos aparentemente desconectados?

Com o objetivo de aplicar uma abordagem inspirada na História Global a um pequeno corpo documental, realizaremos um breve percurso sobre diferentes construções teóricas, sem a pretensão de apresentar um catálogo extensivo. $\mathrm{Na}$ primeira seção, apresentarei algumas estratégias formuladas pela historiografia diante do desafio de trabalhar com uma delimitação espacial em macroescala. $\mathrm{Na}$ segunda seção, sempre de forma breve, comentarei tentativas recentes de estudo da História Global a partir do conceito de "globalização". Na seção final, partindo da atuação comercial das grandes companhias florentinas do século XIV, um possível modelo teórico será elaborado, com o único intuito de defender poucos preceitos fundamentais da investigação em história econômica das sociedades europeias da Baixa Idade Média inspirados em uma abordagem global.

\section{USOS DA MACROESCALA COMO UNIDADE DE OBSERVAÇÃO}

Dois problemas iniciais se colocam para toda investigação historiográfica: a delimitação dos marcos temporais e a delimitação dos marcos espaciais. Civilização material, economia e capitalismo (BRAUDEL, 1979) trata de forma diferente esses dois desafios. A delimitação dos marcos temporais segue um princípio de maior rigidez, tratando como conjunto os séculos XV a XVIII. Já na delimitação dos marcos espaciais, Braudel opera com quatro escalas diferentes. Tendo a Europa como objeto de investigação, os dois primeiros capítulos procuram definir o espaço desse continente na história da ocupação do planeta pela espécie humana, partindo de uma tipologia de sociedades assentadas em cinco diferentes formas de exploração dos recursos 
naturais. Na apresentação de uma cartografia global (BRAUDEL, 1979, v. 1, p. 56-57) encontramos uma proposta de classificação de sociedades a partir de uma estrutura econômica fundamentada em:a)caça, pesca e colheita; b) pastorio eagricultura nômade; c) agricultura de arado simples; d) agricultura avançada, com técnicas de dominação dos recursos hídricos; e) agricultura complexa, com alta densidade populacional, canalização e charrua de tração animal. Nesse sentido, o historiador propõe um critério capaz de esboçar zonas de similaridade entre sociedades assentadas em diferentes continentes. Sociedades com uso de agricultura de arado simples são identificadas na América do Sul, na América do Norte, e no Extremo Oriente; a estrutura econômica assentada na pesca, na caça e na colheita permitiria o estudo conjunto de sociedades existentes na Oceania, no centro-sul e sul da América do Sul, no nordeste da América do Norte e no sul da África. Em primeiro lugar, a tipologia permitiu ao historiador enquadrar em uma única classificação diferentes cidades e sub-regiões existentes no continente europeu. Mas, não menos importante, forneceu um quadro teórico capaz de possibilitar uma abordagem comparativa coerente entre sociedades existentes em diferentes espaços continentais, desde que pertencentes à mesma categoria. Assim, Braudel (1979, v. 1) propôs três espaços civilizacionais da agricultura avançada e complexa: a "civilização do trigo", do continente europeu; a "civilização do arroz", no continente asiático; e a "civilização do milho", no continente americano. Apesar de não ser objetivo da obra, o jogo de comparações entre as civilizações da agricultura avançada-complexa aparece diversas vezes nos três volumes de Civilização material, economia e capitalismo, e funciona para o historiador propor uma verdadeira agenda de investigações a ser feitas: a comparação entre a rede urbana da Europa com a rede urbana do norte da África; a existência do "capitalismo" (como definido pelo autor) no Mediterrâneo e nos corredores de comércio transasiático; a similaridade entre o circuito de feiras e mercados na Europa Ocidental e nos planaltos do vasto território chinês.

Proposição teórica oposta está na excelente coletânea de artigos organizada por Arjun Appadurai (1996), fundamentada na distinção entre "sociedades capitalistas" e "sociedades pré-modernas". Os autores procuram aplicar um modelo teórico comum às últimas, pensando em termos semelhantes o funcionamento monetário e a circulação de mercadorias, seja na sociedade Tiv pré-colonial, no norte da Nigéria, seja na sociedade carolíngia europeia. A teoria de "sociedades pré-modernas" pretende, portanto, fornecer ferramentas para um estudo em escala global. Adespeito da excelente qualidade dos trabalhos apresentados, é possível defender que essa categorização dualista é ainda mais problemática do que a tipologia proposta por Braudel, aplainando em uma mesma definição estruturas socioeconômicas irredutíveis. Como pensar sob a mesma categoria (de "pré-moderno") estruturas tão distintas, como a eficaz economia de caça e coleta de sociedades nômades (SAHLINS, 1974), os mecanismos estatais de distribuição e redistribuição da produção nos impérios mesopotâmicos da Antiguidade (LIVERANI, 2011), e a industrious revolution que transformou a produção, os circuitos de circulação e os níveis de consumo da sociedade europeia pré-industrial entre os séculos XVII e XVIII (DE VRIES, 2009)?

Os modelos teóricos radicalmente diferentes e irredutíveis de Braudel e Appadurai são de grande interesse para uma perspectiva de investigação global da Idade Média. Na obra braudeliana, o historiador procura um conjunto de critérios que permitam organizar, classificar e segmentar a multidão heterogêna das sociedades do planeta em um modelo teórico coerente e articulado. Na coletânea de Appadurai, 
encontramos a identificação de um elemento social (a mercadoria) presente em sociedades diferentes no tempo e no espaço - e que permite, portanto, uma investigação em conjunto dessas sociedades. Para retomarmos a pintura de Hieronymus Bosch a partir de uma metáfora, podemos dizer, de forma um pouco canhestra, que Braudel procura unificar os elementos dispersos e desconectados pela construção de uma moldura; Appadurai, ao contrário, procura a figura de um "Santo Antão" que apareça em diferentes espaços da tela, exercendo o papel de unificador do heterogêneo.

A abordagem de Appadurai parece contar, atualmente, com maior influência. O Medieval Institute Publication (Western Michigan University) iniciou, em 2014, a publicação de um periódico e de uma linha editorial voltados para o tema da Idade Média em perspectiva global; ${ }^{1}$ a primeira publicação, do mesmo ano, apresenta uma coletânea de dezoito artigos engajados em repensar a peste negra (GREEN, 2014). Da mesma forma, Dennis Flynn, em artigo publicado em 2015, encontra na prata o elemento capaz de unificar a investigação em escala global. Elaborando um modelo teórico denominado "teoria unificada de preços", com o intuito de compreender as dinâmicas de oferta e demanda, o historiador defende a ideia da formação de um mercado da prata em escala global no século XVI, integrando a produção na América Espanhola, a circulação no espaço europeu, e a demanda intensiva em território chinês (FLYNN, 2015). Embora louvável, o experimento teórico de Flynn não é inteiramente convincente, uma vez que a produção, a circulação e os usos da prata são abstraídos dos processos econômicos locais e regionais de que participam. Problemas ligados à estruturação de uma sociedade colonial com uso de trabalho compulsório e participação ativa das culturas ameríndias na América do Sul (STERN, 1982), e as profundas transformações das redes mercantis na Europa (BOXER, 2006) - processos indissociáveis da formação de circuitos de produção e circulação da prata desaparecem da narrativa. Os protagonistas são apagados em um grande mecanismo de oferta e demanda planetária. Estamos diante dos limites da perspectiva da História Global que procura identificar, em um único elemento da vida socioeconômica, o fio condutor da investigação. Ademais, salvo engano, a existência de um evento como a peste negra parece ser excepcional: como a epidemia atingiu três continentes, torna-se evidente a importância de uma abordagem "global". ${ }^{2}$ No artigo de Flynn, a prata é interconectada e articulada entre os espaços de todo o planeta, mas desconectada e desarticulada de todos os elementos políticos e econômicos ligados, por exemplo, aos fenômenos monetários locais.

O próprio texto de Fernand Braudel (1979) contém outra saída. Mencionamos que o historiador trabalha a partir de quatro escalas espaciais. Após apresentar sua cartografia global, a escala planetária desaparece; e, nos três volumes que compõem sua obra, prevalece uma alternância contínua entre três escalas de observação: a economia-mundo, o regional, e o local.

O conceito de economia-mundo trabalha com uma unidade de observação superior às fronteiras nacionais, mas inferior à escala planetária; é um instrumento

\footnotetext{
${ }_{1}^{1}$ As informações da proposta e o link para o periódico e para as publicações podem ser encontrados no site oficial do instituto, disponível em: https://scholarworks.wmich.edu/tmg/. Acesso em: 17 jul. 2019. ${ }^{2} \mathrm{Na}$ verdade, transcontinental, posto que, surpreendemente, não encontramos menção à epidemia que se inscreve entre as três piores da História e que, talvez, tenha influenciado de forma mais decisiva os destinos da humanidade: o conjunto de doenças que dizimou as populações ameríndias das Américas e foi determinante para o processo de colonização europeia desse continente (ALENCASTRO, 2006).
} 
teórico que identifica, em determinados espaços e períodos históricos, o funcionamento articulado e conectado de um espaço econômico heterogêneo e coerente - "uma espécie de unidade orgânica" (BRAUDEL, 1979, v. 3, p. 22). A formação de uma economia-mundo, com sua amplitude e intensidade específicas, é indissociável dos processos de transformação histórica. É preciso ressaltar que não se trata apenas de sair dos estudos locais e passar a trabalhar em escalas espaciais mais amplas; antes, a ideia-chave da economia-mundo está em mostrar como processos que ocorrem em escala local só podem ser compreendidos se analisados a partir de uma perspectiva macroespacial. Nesse sentido, a "economia-mundo do Mediterrâneo" do século XVI - espaço conflagrado por intensos conflitos políticos (o Império Espanhol e o Império Turco), por profundas diferenças culturais e religiosas, e fragmentado por singularidades locais - é entendida como possuidora de uma organicidade resultante, em nível basilar, das estruturas geográficas, e, em nível histórico, das interações contínuas entre as esferas da produção do mundo material, das redes de comércio, e dos tipos e gêneros de produtos utilizados e consumidos (BRAUDEL, 1990). Finalmente, importa mencionar que a concepção de "longa duração", destinada a grande sucesso na historiografia, não surge de forma vaga na obra braudeliana, mas indissociavelmente ligada às estruturas que definem a economia-mundo. Se tais estruturas se transformam de maneira lenta, os eventos políticos, ao contrário, seguem uma dinâmica temporal de grande velocidade, com rupturas e reviravoltas frequentes.

O conceito de economia-mundo está na origem de duas importantes formulações: o Sistema Atlântico e o Moderno Sistema-Mundo. Em ambas, a ideia original de uma "unicidade orgânica" proposta por Braudel é repensada em termos de uma economia de caráter sistêmico. Não é pelo estudo isolado dos elementos (formas de exploração do trabalho, estatuto da propriedade da terra, formas monetárias, técnicas contábeis, transformação tecnológica, fluxos de mercadoria), mas a partir de sua complexa integração que se realiza o movimento de investigação econômica. Trata-se, portanto, de uma metodologia diametralmente oposta à de Arjun Appadurai. Robin Blackburn (1998), trabalhando com o conceito de Sistema Atlântico, identifica como a difusão de plantations escravistas no continente americano, entre os séculos XV e XVIII, resultou da interação sistêmica (e frequentemente bélica) entre protagonistas atuando em diferentes espaços e continentes: nas fachadas marítimas da América do Norte e do sul e nas ilhas do Caribe (envolvendo colonizadores e autóctones); na África subsaariana (com diferente participação das sociedades africanas); e na Europa (com atuação decisiva dos agentes da expansão marítima e comercial e dos poderes políticos rivais). A teoria do Sistema-Mundo, formulada por Immanuel Wallerstein (1974), defende a ideia de que uma estrutura sistêmica, de caráter capitalista, começou a se formar entre os séculos XVI e XVII, a partir da construção de uma hierarquia espacial (centro, semiperiferia e periferia), da divisão internacional do trabalho (livre, compulsório e escravo), e da circulação de diferentes tipos de mercadorias (pessoas em situação escrava, produtos alimentícios, matérias-primas e manufaturados). Em três volumes posteriores, o autor defende a ideia de que o Moderno Sistema-Mundo passou por um processo contínuo de transformação interna, com intensificação do predomínio do sistema capitalista no tecido social, e de contínua expansão, alcançando, nos séculos XIX e XX, funcionamento em escala global (WALLERSTEIN, 1980, 1989, 2011). A força desses modelos teóricos, assentada na capacidade de analisar os eventos locais a partir de uma escala de observação transcontinental, e na formulação de uma arquitetura conceitual refinada e coerente, fez com que se tornassem trabalhos 
de referência no campo da História Global. Entretanto, por diferenciar um processo histórico que ocorre somente a partir do século XVI, o investigador de história econômica do medievo se vê diante de um poderoso instrumento conceitual que, a princípio, não está ao seu alcance.

\section{DA HISTÓRIA GLOBAL À TEORIA DA GLOBALIZAÇÃO}

A coletânea de artigos organizada por Andre Gunder Frank e Barry Gills, em 1996, teve como objetivo ser um divisor de águas na chamada História Global. Os dois autores, partindo dos trabalhos de Wallerstein, argumentam que a constituição de um Sistema Mundo pode ser identificada em 1500 a.C., quando "relações entre o Egito e a Mesopotâmia deram origem ao que [David Wilkinson] denomina 'Civilização Central', e que não parou de expandir incessantemente pelo mundo desde então" (FRANK; GILLS, 1996, p. 4, tradução nossa). Duas características centrais definem - Sistema Mundo: as conexões de diversa natureza (comercial, militar, cultural) em escala intercontinetal (Ásia, Europa e África), e a presença de quatro processos: a) acumulação de capital; b) constituição de uma estrutura de poder e relações de centro e periferia; c) alternância entre períodos de hegemonia de uma potência, e períodos de intensa rivalidade entre múltiplos centros; d) ciclos econômicos, alternando períodos de crescimento e de retração. Entretanto, o "Moderno Sistema-Mundo" de Wallerstein, e o "Sistema Mundo" de Frank e Gills, mais que diferentes, são teorias irreconciliáveis:

O meu "Sistema-Mundo" não é um sistema "no mundo" ou "do mundo". É um sistema "que é um mundo". Daqui a utilização do hífen, posto que 'mundo' não é usado como um atributo do sistema. Ao contrário, as duas palavras reunidas constituem um único conceito. O sistema de Frank e Gills é um Sistema Mundo em um sentido atributivo, no sentido de que tendeu, durante o tempo, a se irradiar por todo o planeta. Esses autores não concebem uma multiplicidade de "sistemas-mundo" coexistindo no planeta. Porém, eu defendo que, até o século XIX, era justamente esse o caso (WALLERSTEIN, 1996, p. 294-295, tradução nossa).

As diferenças, porém, são mais profundas. O caráter sistêmico de Wallerstein decorre da conexão econômica que realiza a transformação de diferentes estruturas de produção no interior do sistema. Sendo assim, há uma importância fundamental em identificar dois diferentes tipos de comércio: aquele que efetiva, entre as partes envolvidas, a integração produtiva, e aquele que não efetiva tal integração. Trata-se de uma abordagem fundamentada em critérios econômicos, e a categoria de "capitalismo" é de primeira importância para a definição do "Moderno Sistema-Mundo". Já para Frank e Gills, a identificação do Sistema Mundo ocorre apenas pela constatação da rede de trocas, não necessariamente comerciais, ocorrendo em escala transcontinental. A teoria desses autores participa pouco dos debates sobre o surgimento do capitalismo. É mais pertinente identificá-la com a chamada Big History, a história da espécie humana. O Sistema Mundo tem como objetivo se contrapor aos modelos teóricos de Oswald Spengler e Arnold Toynbee, que interpretavam a 
ocupação do Homo sapiens no planeta como uma sucessão de grandes civilizações (McNEILL, 1996). Afirmam os autores:

Arnold Toynbee [...] elenca 19 ou 21 civilizações separadas. [...] Ele rejeita "a egocêntrica ilusão equivocada da unidade da história - decorrendo da suposição de que existe apenas um rio civilizacional, o nosso". [...] Nós sugerimos que há um rio comum e uma unidade na história, no interior de um único Sistema Mundo, multicultural em sua origem e em sua manifestação (FRANK; GILLS, 1996, p. 17, tradução nossa).

Os autores realizam menos uma exposição descritiva da evolução do Sistema Mundo do que uma agenda de investigação imbuída de realizar o empreendimento. É possível, porém, inscrever na esteira do ideário de Frank e Gills o louvável esforço feito por Janet Abu-Lughod (1989) em descrever o suposto Sistema Mundo existente entre 1250 e $1350 .{ }^{3}$ Porém, torna-se difícil identificar o trabalho de Abu-Lughod como pedra fundamental dos estudos medievais em História Global. A autora esboça uma interessante cartografia afroeurasiática contendo oito "subsistemas" que, a partir de pontos de contato, formaria uma totalidade sistêmica. Mas o livro se caracteriza pela inconsistência teórica, incluindo a incompreensão dos modelos de Braudel e Wallerstein. Ao cabo, a autora compartilha dos pressupostos de Frank e Gills: a mera constatação de um fluxo de trocas comerciais é suficiente para caracterizar um "Sistema Mundo". A exposição monográfica de cada subsistema é destituída de maior análise documental e, ao término da leitura, é difícil entender por que as feiras de Champagne são "um dos principais centros da economia-mundo do século XIII" (ABU-LUGHOD, 1989, p. 55, tradução nossa). ${ }^{4}$

A abordagem de Frank e Gills cruzou com uma teoria que, conquistando notoriedade no decorrer da década de 1990, se consolidaria como um verdadeiro campo de estudos: a teoria da globalização. Aqui, podemos tomar duas obras como exemplo. Publicada em 2019, a partir do esforço coletivo de oito autores, The Big History of Globalization compartilha a mesma perspectiva de reunir a ideia de unidade na história com a história da espécie humana. O livro se coloca como sucessor da agenda de Frank e Gills, propondo a expansão contínua do processo de globalização em cinco etapas sucessivas: o período de globalização arcaico, entre a revolução Neolítica até 1000 d.C.; o período protomoderno, de 1000 a 1800; e o período moderno (ALESHKOVSKI et al., 2019). O primeiro período, para os autores, se caracteriza pela formação de um Sistema Mundo afroeurasiático que, a partir da difusão de três tecnologias (a metalurgia, a escrita, e a governança burocrática), teriam alcançado o auge entre 1200 e 150 a.C. Os séculos posteriores da Antiguidade Clássica e a Alta Idade Média ganham o honroso título de "o milênio perdido" (ALESHKOVSKI et al., 2019, p. 33-34). Já os séculos XIII e XIV, realizando a "revigoração" do Sistema Mundo afroeurasiático, apenas prepararam o auge do "período protomoderno", iniciado com a Era dos Descobrimentos. Seja como for, os autores definem três características da tal globalização existente entre 1000 e 1800. Primeiro, a existência de interações entre

\footnotetext{
${ }^{3}$ Abu-Lughod, de fato, participa com artigo no livro de Frank e Gills.

${ }^{4}$ Como se vê, a autora utiliza de forma abusiva o conceito de Braudel de economia-mundo.
} 
as sociedades do Sistema Mundo afroeurasiático. Não existe, aqui, nenhum esforço para diferenciar tipos ou diferentes níveis de intensidade de conexões; é o mesmo critério que permite, aos autores, pressupor a formação da História Global desde a Revolução do Neolítico. Em segundo, a identificação de que todas as sociedades são sujeitas a um ciclo simples de três fases (crescimento, crise e queda), que, ocorrendo de forma sincrônica, permitem uma observação de momentos de crescimento e crise da totalidade do Sistema Mundo. Finalmente, os autores caracterizam todas as sociedades desse vasto período como "complexas sociedades agrárias" aprisionadas na "armadilha malthusiana". Os autores procuram mostrar uma teoria de ciclos sociodemográficos, requentando, sob ilusão de novidade, a tradicional ideia de que o crescimento demográfico, em um cenário de ausência de inovações tecnológicas, levaria à exaustão dos recursos naturais, precipitando um ciclo de crises famélicas, epidemias e queda populacional (ALESHKOVSKI et al., 2019, p. 58-67).

The Big History of Globalization oferece uma ótima ocasião para os medievalistas participarem do debate. Parece-me um tipo de historiografia que, se não comete, ao menos se aproxima de cometer quatro proposições problemáticas. Primeiro, o chamado argumento straw man. Postulando que o processo de transição do "Sistema Mundo afroeurasiático" (Afroeurasian world system) para o "Moderno Sistema-Mundo Global" (Modern Global world-system) foi "detalhadamente descrito por Fernand Braudel [...], Samir Amin [...], Giovanni Arrighi [...], Andre Gunder Frank [...], Immanuel Wallerstein", os autores operam franca confusão e deturpação de diferentes modelos teóricos (ALESHKOVSKI et al., 2019, p. 26). Como vimos, não é possível equalizar teorias diferentes (Braudel e Wallerstein) ou mesmo radicalmente opostas (Frank/ Gills). Em segundo lugar, há visíveis traços de teleologia na tentativa de identificar as sementes da globalização no Neolítico, naturalizando, na história humana, um modelo teórico criado para descrever, sobretudo, os processos que passaram a se acirrar após a queda do muro de Berlim (CASTREE et al., 2004). Em terceiro, voltamos, aqui, a flertar com a velha "história dos vencedores". Trata-se de uma curiosa forma de fazer História Global: apagando dos registros tudo e todos aqueles que não tenham participado (ou que tenham interrompido) o processo teleológico da globalização.

É importante ressaltar que essa perspectiva se contrapõe de maneira irreconciliável com a cartografia do globo apresentada por Fernand Braudel; mais do que diferença metodológica, a própria concepção de escrita da história é oposta. $\mathrm{Na}$ tipologia apresentada por Braudel, a despeito de diversos problemas, o historiador não apenas procura estar atento à heterogeneidade de formações sociais dispersas pelo planeta, mas, sobretudo, não realiza uma relação de hierarquia entre as diferentes categorias tipológicas. Chegamos, aqui, ao quarto aspecto problemático de The Big History of Globalization: uma concepção temporal linear e esquemática. É um tempo histórico achatado; a narrativa de vastíssima duração apenas agrega eventos que reiteram e justificam a própria narrativa - forma de trabalho pouco funcional quando trabalhamos com documentação primária. É nesse sentido, por exemplo, que evocamos, na primeira seção, o conceito de multiplicidade temporal, ou seja, de um tempo histórico composto por múltiplas camadas e por múltiplas velocidades. O ritmo temporal das transformações políticas não tem, por exemplo, o mesmo ritmo temporal das transformações das estruturas da vida cotidiana (BRAUDEL, 1979). A ideia de multiplicidade do tempo histórico se mostrou bastante fecunda para a historiografia posterior (TOMICH, 2011). Também serviu como ponto de contato entre o trabalho efetivamente historiográfico e as tradições de pensamento (da filosofia ou da sociologia) 
que estudam o fenômeno temporal de uma perspectiva qualitativa - recuperando, por exemplo, o conceito de "contemporaneidade do não contemporâneo" elaborado por Ernst Bloch na década de 1930 (SCHWARTZ, 2001).

Partindo do mesmo problema da globalização como um processo histórico de longa duração, Globalization as Evolutionary Process, publicado em 2007 por Tessaleno Devezas, George Modelski, e William Thompson, apresenta uma organização teórica bastante diferente. Os autores iniciam com uma saudável reflexão sobre a construção de diferentes definições de globalização nas últimas décadas, apresentam os críticos desse conceito, e, ao cabo, expõem seu posicionamento. Tratando-se de um processo de duração milenar, a globalização, para os autores, se define por duas características: uma intensificação das interconexões (políticas, econômicas ou culturais), mas, sobretudo, pela difusão de instituições de atuação em escala global. Em termos históricos, o período medieval europeu não participa diretamente da história desse processo; nos séculos XIII e XIV, ocorreria um primeiro experimento na Ásia, de curta duração, de uma globalização que só começaria verdadeiramente a partir das navegações marítimas do século XVI (DEVEZAS et al., 2008). Os autores rejeitam a teoria que estende a história global até o período neolítico, e propõem a distinção entre dois processos distintos: a "continentalização", que, iniciada na Antiguidade, alcançaria uma intensificação nas dinâmicas de trocas intercontinentais no período que vai de 500 a.C. a 500 d.C.; e a globalização posterior (DEVEZAS et al., 2008, p. 419).

As três teorias, portanto, colocam o medievalista diante de três problemas diferentes. A teoria do Sistema Mundo, de Frank e Gills, define as sociedades europeias dos séculos $\mathrm{V}$ a $\mathrm{XV}$ como periferia de reduzida importância em sentido temporal (porque os processos mais importantes ocorreram na Antiguidade ou na época moderna), e em sentido espacial (porque o centro de difusão do sistema decorreria na Ásia). O argumento, além de pouco convincente, se aproxima do abismo disfarçado de julgamento moral que divide sociedades "mais importantes" e sociedades "menos importantes" para a história humana. The Big History of Globalization nos desperta para a necessidade de manifestar com maior visibilidade que termos como "idade das trevas" ou "esquema malthusiano" há muito perderam força interpretativa. Finalmente, a teoria exposta por Modelski, Devezas e Thompson conduz o medievalista para fora do debate da História Global - sem dúvida a resolução mais cômoda, mas não inteiramente satisfatória. Gostaria de argumentar que esses três problemas espinhosos são exatamente as principais razões para motivar os pesquisadores em História Medieval a refletir sobre a História Global não apenas no sentido de colocarmos nossos pontos de vista, mas, sobretudo, para transformar nossas próprias abordagens.

\section{O GLOBAL E A ABORDAGEM DO LOCAL: AS CONEXÕES MERCANTIS}

Não existem asas de Dédalo que nos possibilitem escapar com facilidade do labirinto de modelos apenas mencionados nas páginas deste artigo. Não vejo outra saída senão apostar em um caminho existente e segui-lo. Portanto, aproveito para enunciar com transparência o conjunto teórico que servirá como ponto de partida para tentar tratar das fontes com uma perspectiva global em história econômica: 
não os trabalhos ligados à Big History recente, enunciados na segunda seção (o Sistema Mundo de Frank e Gills ou a Globalização), mas à tradição historiográfica que enfrenta o problema da macroescala como unidade de observação. Isso significa dizer, em primeiro lugar, que assumirei como princípio as argumentações de Immanuel Wallerstein e Fernand Braudel. Ou seja, não é possível pensar, na Baixa Idade Média, em termos de uma estrutura econômica de funcionamento sistêmico; e, independentemente da maior ou menor exatidão da tipologia braudeliana, que o planeta se constituía em uma multiplicidade fragmentada de formações sociais radicalmente diferentes. $\mathrm{E}$, no entanto, não faltam fontes primárias indicando a consistência de conexões de longo alcance.

No manuscrito produzido por Francesco Pegolotti, agente comercial da Companhia Bardi de Florença (EVANS, 1936), conhecido atualmente como La Pratica della Mercatura, encontramos as seguintes informações sobre a realização do comércio em Trebizonda:

Os pesos e as medidas de Trebizonda são os mesmos utilizados em Tabriz.

Toda especiaria grossa se vende a libbra grossa, ou seja, a ruotoli.

Toda especiaria miúda se vende a once grosse [...]

Os tecidos se vendem em Trebizonda a picchio.

A prata se vende a libbre sottile.

[...] Quem porta mercadoria a Trebizonda e vende na própria terra, paga ao imperador da Trebizonda 3\% (3 per centinaio), mas se vender a genovês ou outro cristão do Ocidente (genti latine), não paga tributo.

Porém, se a mercadoria aportada em Trebizonda não é vendida na terra, mas transportada pessoalmente ou expedida para Tabriz, se paga ao dito imperador 28 aspri por carga (per soma), e ainda 1 aspri por carga ao cônsul.

[...] 1 ruotoli equivale, em Pera, a 15 libbre. E se deve calcular que, para transportar de Pera a Trebizonda em embarcação armada, pode alcançar o custo do frete $100 \%$ a pimenta, e $50 \%$ o fardo de tecido, e de Trebizonda a Pera, em embarcação armada, a pimenta $150 \%$ em cântaro genovês, e a seda e os tecidos de ouro de $50 \%$ a $75 \%$; em embarcação desarmada, o custo do transporte se reduz à metade (PEGOLOTTI, 1936, p. 31-32, tradução nossa). ${ }^{5}$

O longo trecho é um exemplo rico de evidências de um verdadeiro sistema comercial em funcionamento. Encontramos o fluxo de mercadorias entre três regiões distintas: a) Tabriz, atualmente localizada no Irã; b) Trebizonda, capital de império de mesmo nome e que, situada no mar Negro, servia como ponto central de circulação mercantil; e c) Pera, atual Beyoglu (Istambul), porto de controle e passagem entre o mar Negro e o Mediterrâneo Oriental. A equivalência de pesos e medidas entre Tabriz

\footnotetext{
${ }^{5}$ Como a tradução do trecho apresenta dificuldades, optei por manter no original as denominações de pesos e medidas (mesmo quando cognatos), e por incluir entre parêntesis, nas passagens mais discutíveis, o original. A soma, traduzida por carga, indicava a quantidade levada no dorso do animal de transporte.
} 
e Trebizonda, distantes cerca de $820 \mathrm{~km}$, aponta para um fluxo comercial tradicional e regular. Pegolotti aponta três mercadorias que, oriundas do Mediterrâneo, tinham como destino a rota Trebizonda-Trabiz: prata, tecidos, especiarias; no fluxo contrário, pimenta, seda e tecidos de ouro. Além da operação da companhia florentina a partir do testemunho de Pegolotti, encontramos menção a genoveses e outros mercadores da cristandade latina. De fato, a ausência de uma frota mercantil levava os florentinos a expedir mercadorias em embarcações genovesas, pisanas ou venezianas (BRESC, 1986). Finalmente, a existência de um comércio regular não significava a ausência de altos custos de transporte, entrevisto na necessidade de expedir mercadorias em embarcações armadas.

A participação de mercadores italianos nos fluxos de comércio do mar Negro segue lógica análoga à descrita por David Jacoby (2005), a respeito das operações mercantis de Veneza realizadas entre o Egito e o Império Bizantino. Trata-se, nos dois casos, da existência de redes comerciais de tradição secular, em que os mercadores da penísula itálica passaram a se inserir paulatinamente; e, nesse sentido, Janet Abu-Lughod (1996) tem razão sobre a necessidade de "des-eurocentrizar" as abordagens feitas pela historiografia europeia, passando a colocar em primeiro plano os agentes mercantis do norte da África, do Levante, da Ásia Central e da Europa Oriental. Dito isso, é possível acrescentar a necessidade de "des-essencializar" o comércio, ou seja, usar esse termo não tanto como categoria universal, que equaliza eventos ocorridos em sociedades e períodos diferentes, mas sim como uma categoria histórica, que se transformou no tempo e no espaço.

A entrada de agentes italianos nos circuitos mercantis do Mediterrâneo Oriental e do mar Negro decorreu em três escalas diferentes. O fluxo migratório possibilitado pelas cruzadas permitiu a multiplicação de um comércio difuso, de pequena escala, realizado ocasionalmente por todos os tipos de viajantes, como peregrinos, militares e embaixadores (JACOBY, 2005). Em escala mais profissional, mercadores individuais ou organizados em pequenas e breves associações (raramente superior a três sócios) podiam "tentar a sorte". Caso emblemático é o do cambista florentino Lippo del Sega; acostumado, na década de 1310-1320, a ganhar dinheiro a partir de operações de câmbio e de depósito bancário, Lippo é atingido por uma "má conjuntura" no mercado monetário; a desvalorização do florin atinge em cheio seus negócios. O cambista decide, então, viajar para o Chipre em 1322 (RONCIĖRE, 1973). Os poucos indícios existentes apontam que, nessa empreitada, o cambista florentino não tenha jamais entrado nos circuitos de comércio de tecidos ou especiarias do Mediterrâneo Oriental; como seu know how estava ligado aos metais preciosos, Lippo procurou lucrar manipulando moedas de ouro bizantinas, escavando ganhos a partir da diferença de valor entre o ouro e a prata em diferentes praças comerciais. Seja como for, a estadia não parece ter sido muito proveitosa; em 1323, após passar por Veneza, já estava de retorno à Toscana (RONCIĖRE, 1973). O importante aqui é que, nessa escala profissional de operações, os mercadores tendiam a escolher um (ou poucos) tipo(s) de mercadoria(s), trabalhavam com índices modestos ou medianos de capital e lucro, e agiam com alto nível de mobilidade e fluidez - uma conjuntura ruim, um negócio malsucedido, e o perigo e o desconforto das viagens eram circunstâncias que podiam reduzir o tempo dos negócios a não mais que um ano de duração.

A realidade descrita em La Pratica della Mercatura é bastante diferente. Francesco Pegolotti não agia como mercador indepentente; participava como agente (bem) remunerado de uma das grandes companhias florentinas. Edwin Hunt (1994), 
ao se referir ao seleto grupo das grandes empresas - Bardi, Peruzzi, Acciaiuoli, Buonaccorsi, Scali, Frescobaldi, Alberti -, propõe a designação de "supercompanhias" apenas para as três primeiras, levando em consideração o volume de capital e a amplitude espacial de suas operações. A companhia Peruzzi, por exemplo, apresentava uma carteira de negócios com atividades em Maiorca, Barcelona, Avignon, Paris, Bruges, Londres, Gênova, Veneza, Pisa, Nápoles, Palermo, Túnis, Barletta, Ragusa, Chiarenza, Pera, Rhodes e Chipre (HUNT, 1994). A atuação de mercadores individuais não pode ser comparada com a escala de atividade dessas companhias - por isso a insistência, acima, de estarmos atentos ao engodo da palavra "comércio", designando da mesma maneira eventos distintos. Há comércio e comércio. No caso das companhias florentinas, a capacidade de mobilizar grandes somas de capital permitiu: a) negócio com diferentes tipos de mercadorias em uma praça comercial; b) fluxo entre diferentes praças comerciais; c) manutenção dos negócios em conjunturas adversas; e d) fluxo regular do comércio. Dizendo de forma algo esquemática, podemos afirmar que enquanto os mercadores independentes têm maior dependência de conexões já consolidadas, as grandes companhias florentinas tinham capacidade de consolidar novas conexões.

Assim parece ter ocorrido no comércio de trigo. É preciso tornar claro, em primeiro lugar, que os níveis de atividade em cada praça comercial eram bastante desiguais. Em 1335, as principais agências da companhia Peruzzi se localizavam em Nápoles, Palermo, Barletta, Avignon, Paris e Londres; apenas a primeira praça operava em escala de valores superior a todas as agências secundárias. ${ }^{6}$ Para Edwin Hunt (1994), após análise dos livros de contabilidade, o período de intenso crescimento das duas principais agências ocorreu durante as décadas de 1290 e 1310, ancorado em um negócio bastante específico: a importação de trigo do sul para o norte da Itália. David Abulafia (1981) identificou carregamentos de grande volume partindo dos portos do Reino de Nápoles; o maior registro, de 1311, refere-se à exportação excepcional de cerca de 45 mil toneladas de trigo; em 1294, há registro de 2.250 toneladas; e, em 1308, de 4.730 toneladas de trigo exportado. Os lucros obtidos com essas operações de grande dimensão permitiram às companhias florentinas o acúmulo de capital necessário para expandir suas atividades em outras praças comerciais. Em todo caso, a documentação sugere que o volume de negócios no Mediterrâneo Oriental ou no mar Negro jamais chegou perto de alcançar aqueles valores. Na década de 1330, a companhia Peruzzi passou a investir de maneira maciça em outro negócio: a exportação de lã inglesa (HUNT, 1994).

A exportação de grandes volumes de trigo funcionava de maneira sistêmica, porque só podia se realizar a partir de uma sincronia de elementos: a capacidade produtiva do sul da península itálica; a existência de companhias capazes de organizar um fluxo regular de grande quantidade de mercadorias; a existência de frotas e portos instalados; a cunhagem regular de moedas; acordos diplomáticos e licenças de comércio; além de uma maciça demanda. Entretanto, é preciso estabelecer uma diferença importante entre os funcionamentos sistêmicos do comércio e de uma economia. Neste último caso, a integração comercial ocorre em conjunto com

\footnotetext{
${ }^{6}$ Em 30 de junho de 1335, a agência Peruzzi, de Nápoles, tinha por receber 74.092 liras (li.), e 120.960 li. a pagar; as agências de Rhodes, Chipre, Maiorca, Sardinia, Tunis, Veneza e Pisa tinham, no total, 73.852 li. a receber, e 58.256 li. a pagar (HUNT, 1994, p. 181).
} 
a integração produtiva, o que significa dizer que é possível reconhecer mudanças nas estruturas agrárias ou de fabricação (manufatureira ou industrial) locais, em decorrência de dinâmicas que se passam em escala global (WALLERSTEIN, 1974). Nos circuitos comerciais aqui referidos, não parece possível realizar tal afirmação.

Não há indícios de uma transformação agrária na Toscana que decorrem da consolidação de um sistema de importação de trigo do reino de Nápoles ou da Sicília. Temos, antes, a intensa demanda de Florença. A cidade, então com uma população superior a 100 mil habitantes (DAY JR., 2002), controlava um território capaz de suprir com apenas cerca de $42 \%$ de sua demanda por trigo (LENZI, 1978). A carestia de 1329 oferece um ótimo quadro de observação. À medida que se evidencia, nos primeiros meses, o segundo ano consecutivo de péssima colheita, os preços começam uma escalada intensiva. Em abril, a cidade é atingida pela falta de trigo (LENZI, 1978). As autoridades públicas iniciam uma série de medidas, enquanto as ruas são tomadas pela população à beira da revolta. Em junho, chega trigo da Sardenha, comprada emergencialmente com orçamento estatal. Em setembro, porém, os preços voltam a disparar. E em novembro, a carestia castiga a urbe. As autoridades públicas impõem novas medidas. Em março de 1330, conseguem alcançar uma situação estável, apesar do descontentamento da população diante da péssima qualidade dos novos grãos importados. Em junho chega a nova safra, os preços caem, e o abastecimento urbano é restabelecido (LENZI, 1978).

A escassez de 1329-30, em Florença, é bastante diferente da crise alimentar ocorrida no norte da Europa entre 1315 e 1322. A sucessão de invernos excessivamente rigorosos e de verões excessivamente chuvosos atingiu, ainda que de maneira desigual, vasta área do norte da Europa; a queda sucessiva da produção agrícola, resultante das intempéries climáticas, conduziu à inflação dos preços dos cereais perceptíveis na Inglaterra, em Flandres, no norte da França, e em diversas regiões do império; as crônicas do período relatam a incidência da fome (JORDAN, 1996). A despeito da existência de conexões capazes de cobrir um extenso arco espacial o centeio produzido em Brandenburgo era vendido em Flandres -, Chester Jordan (1996) prefere a hipótese de que a carestia decorreu não da integração de um espaço comercial, mas, sobretudo, da queda generalizada da produção de trigo e de cereais menores. Seja como for, é interessante acompanharmos a evolução dos preços na cidade de Florença (Tabela 1). ${ }^{7}$

Tabela 1 - Oscilação de preço do staio de trigo em Florença

\begin{tabular}{lll}
\hline Data & Preço do staio de trigo & Porcentual de oscilação \\
\hline $4 / 1310$ & 9 soldi e 3 denari & \\
\hline $8 / 1311$ & 14 soldi & $+52,1 \%$ \\
\hline $8 / 1312$ & 14 soldi & - \\
\hline $8 / 1313$ & 13 soldi e 6 denari & $-3,8 \%$ \\
\hline $9 / 1314$ & 12 s. & $-11,2 \%$ \\
\hline
\end{tabular}

\footnotetext{
${ }^{7}$ O preço é dado em 1 staio por soldi e denari. O staio era uma unidade de medida que, no período, continha 24,363 litros, e, quando usado para armazenar trigo, pesava entre 16,9 a 17,6 quilos. 0 sistema de contas era baseado em três unidades: o denari, o soldi e a lira. 1 lira equivalia a 20 soldi e 1 soldi equivalia a 12 denari (BALESTRACCI, 1975/76, p. 71).
} 


\begin{tabular}{lll}
\hline $9 / 1315$ & 8 s. & $-33,4 \%$ \\
\hline $8 / 1316$ & 9 s. 6 d. & $+18,7 \%$ \\
\hline $8 / 1317$ & 13 s. 3 d. & $+38,9 \%$ \\
\hline $8 / 1318$ & 12 s. 10 d. & $-2,9 \%$ \\
\hline $8 / 1319$ & 10 s. 10 d. & $-15,6 \%$ \\
\hline $8 / 1320$ & 8 s. 4 d. & $-23,1 \%$ \\
\hline $8 / 1321$ & 8 s. & $-4 \%$ \\
\hline $8 / 1322$ & 14 s. & $+75 \%$ \\
\hline
\end{tabular}

Fonte: Domenico Lenzi (1978).

Em Florença, o preço, entre 1314 a 1316, teve uma queda em relação aos anos anteriores; o quadriênio anterior (1311-1314) representou um período de alta. Entretanto, Giovanni Villani (1991) narra que as adversidades climáticas que ocorriam na Europa do norte atingiram a produção agrícola toscana em 1316; e, de fato, em 1317 nos deparamos com violenta inflação. O próprio cronista acrescenta que a fome foi evitada pela grande quantidade de alimentos importados por mar "da Sicília e da Puglia", circuito comercial consolidado desde o início do século (VILLANI, 1991, p. 751). Entre 1318 e 1321 encontramos o melhor quadriênio da série, com diminuição regular de preços. A alta de 1322 dá início a um período de alta de preços que se estenderia pelo ano seguinte (LENZI, 1978), resultante do inverno excessivo e da seca (VILLANI, 1991). Seja como for, podemos ficar com duas conclusões. Primeiramente, contra qualquer frágil argumento maltusiano, percebemos como um dos mais populosos núcleos urbanos da Europa conseguiu evitar a fome por meio de circuitos comerciais consolidados. ${ }^{8} \mathrm{E}$, em seguida, a inexistência de integração entre mercados de trigo do noroeste da Europa com mercados da Itália. Se existia um fluxo de cereais entre esses dois espaços, ocorria em volume insuficiente para constituir um sistema comercial.

A questão interessa porque as mesmas companhias florentinas que construíram o centro dos negócios no comércio cerealífico na península itálica, e ampliaram sua atuação no Mediterrâneo, aparentemente não foram capazes de explorar as "oportunidades de negócio" abertas pela carestia e escassez decorrentes da "grande fome" no norte europeu. E, no entanto, no período entre 1310 e 1340, ocorreu o aumento constante da atuação das companhias Bardi e Peruzzi em território inglês, com operações centralizadas em um negócio particular: a exportação de lã. Primeiro, para as cidades manufatureiras de Flandres (MURRAY, 2006); posteriormente, a partir da navegação atlântica (costeira), em direção à Toscana, possibilitando a formação, em Florença, da produção em escala maciça de tecidos laníferos de alta qualidade (HOSHINO, 1980). Embora utilizando matéria-prima procedente de diversas regiões, a fabricação têxtil, que colocou Florença entre as principais cidades exportadoras de manufaturas do período (FIGLIUOLO, 2015), passou a funcionar com uma conexão regular com a produção de lã inglesa. Portanto, em um mesmo espaço de fluxo mercantil - o noroeste da Europa e a península itálica -, podemos identificar a constituição de um entrelaçamento regular de produção de tecido, e, ao mesmo tempo, a ausência de integração no comércio de cereais. Finalmente, é importante ressaltar

\footnotetext{
${ }^{8}$ A questão é um pouco mais complicada e receberá tratamento melhor na dissertação a ser publicada em 2020.
} 
que a construção dessas conexões econômicas teve impacto direto na vida cotidiana das sociedades locais. O negócio de exportação de lã, na Inglaterra, teve não apenas importância central para o fisco do Estado e para as pretensões políticas e militares inglesas no continente, mas também foi decisiva para o processo de crescimento da produção manufatureira, culminando, no século XV, em uma transformação das estruturas econômicas dessa região (CARUS-WILSON, 1987). Na Toscana, a derrota de Pisa na batalha de Meloria (1284) marcou o declínio definitivo dessa República como potência marítima (HERLIHY, 1958); em contrapartida, a expansão comercial, financeira e produtiva de Florença levou não apenas à grande migração de camponeses à procura de oportunidades (DAY JR., 2002), mas foi fundamental tanto para impedir que a República desaparecesse após sucessivos desastres e derrotas militares ${ }^{9}$ como para possibilitar sua expansão política no século XV (NAJEMY, 2006).

\section{CONCLUSÃO}

Podemos encerrar manifestando alguns elementos básicos de uma construção teórica apenas esboçada, mas capaz de auxiliar na investigação econômica da Idade Média em perspectiva global.

A concepção de um tempo histórico múltiplo, constituído por diversos ritmos, nos protegerá da armadilha de preferir um critério econômico, ou político, ou cultural, em desfavor de outro. Diferentes são as velocidades e as amplitudes das conexões existentes entre troca de mercadorias, difusão de ideias, e conflitos políticos; e uma abordagem com perspectiva global que investigue, por exemplo, as Cruzadas, ou os conflitos entre o Império Germânico e as monarquias de Aragão, da Sicília ou de Nápoles, encontrará diferentes problemas, e chegará a diferentes resultados, do que aqueles aqui apresentados.

Do ponto de vista econômico, a ideia de espaços fragmentados, destituídos de integração sistêmica, parece ser um bom ponto de partida para identificarmos as dinâmicas de constituição e disrupção de conexões comerciais. A noção de "rede" tem se destacado para explicar trocas de toda natureza. É possível, a partir daí, sugerir uma imagem um pouco menos vaga: um espaço econômico fragmentado e constituído por diversas "redes" de escala local, e que, a partir da atuação de diversos atores econômicos, tiveram alguns "fios" emaranhados, formando, em escala regional ou transcontinental, interconexões específicas (comércio de trigo; comércio de metais preciosos; comércio de especiarias etc.).

Assim, o comércio de lã e metais preciosos entre Londres e Florença entrelaçava dois longos fios de duas malhas comerciais urbanas essencialmente distintas, destituídas de conexão no tocante a outras mercadorias. Ao identificarmos "linhas" comerciais de maior amplitude, envolvendo grande quantidade de capital, organizações empresariais de alta complexidade e trabalhadores em diferentes espaços - como o consumo na corte de Nápoles da produção florentina de tecidos de lã inglesa -, nós nos defendemos de "generalizar" para toda a economia um conteúdo específico, e postular uma "globalização" dificilmente defensável. Ao contrário, isso seria apagar o mais interessante: produzir uma teoria econômica capaz de explicar

\footnotetext{
${ }^{9}$ A derrota para Castruccio Castracani, de Lucca, em 1325, e o desfavorável armísticio com Mastino della Scala, de Verona, em 1338, tiveram terríveis consequências fiscais para a República de Florença.
} 
a formação de conexões comerciais e da interação de mercados em um universo economicamente fragmentado. Para retomar nossa metáfora inicial, não há uma moldura (como na Economia-Mundo), nem um Santo Antão (um elemento unificador da narrativa). Talvez, seja possível pensar em múltiplos personagens que se repetem em diversos quadros espalhados na parede - mas identificá-los muda a compreensão de cada quadro em particular. E é nisso que está, talvez, a principal contribuição. A identificação de conexões de longo alcance no período medieval não tem nada de novo, e basta lembrar o sucesso e a quantidade bibliográfica atinentes às famosas "feiras de Champagne". Entretanto, a meu ver, entender como fluxos comerciais de longo alcance transformaram definitivamente as sociedades em nível local ainda está por se fazer. E é com isso que gostaria de terminar. A História Global nos obriga a tentar olhar os eventos ocorridos em escala de grande amplitude. E a perspectiva em macroescala será útil, sobretudo, porque poderá nos auxiliar a pensar a transformação dos eventos em escala local.

\section{REFERÊNCIAS}

ABULAFIA, David. Southern Italy and the Florentine Economy, 1265-1370. Economic History Review, London, n. 34, v. 3, p. 377-388, 1981.

ABU-LUGHOD, Janet. Before European Hegemony. Oxford: Oxford University Press, 1989.

ALENCASTRO, Luiz Felipe de. O trato dos viventes. São Paulo: Companhia das Letras, 2006.

ALESHKOVSKI, Ivan et al. A Big History of Globalization. Cham: Springer Nature, 2019.

APPADURAI, Arjun. Introduction: commodities and the politics of value. In: APPADURAI, Arjun (org.). The Social Life of Things. Cambridge: Cambridge University Press, 1996. p. 3-63.

BALESTRACCI, Duccio. Li lavoranti non cognosciuti. Bulletino Senese di Storia Patria, Siena, v. 82-83, p. 67-157, 1975/76.

BLACKBURN, Robin. The Making of New World Slavery. London: Verso, 1998.

BOXER, Charles. A igreja e a expansão ibérica: 1440-1770. Rio de Janeiro: Edições $70,1989$.

BOXER, Charles. O império marítimo português (1415-1825). São Paulo: Companhia das Letras, 2006.

BRAUDEL, Fernand. Civilisation matérielle, économie et capitalisme. Paris: Armand Colin, 1979. 3 v. 
BRAUDEL, Fernand. La Méditerranée et le monde méditerranéen à l'époque de Philippe II. Paris: Armand Colis, 1990.

BRESC, Henri. Un monde méditterranéen: économie et societé en Sicile, 1300-1450. Roma: École Française de Rome, 1986.

CARUS-WILSON, Eleanora. The Woolen Industry. In: MILLER, M.; POSTAN, M. (ed.). The Cambridge Economic History. Cambridge: Cambridge University Press, 1987. v. 2, p. 613-690.

CASTREE, Noel; COE, Neil M.; WARD, Kevin; SAMERS, Michael. Spaces of Work: Global Capitalism and the Geographies of Labour. London: Sage, 2004.

DAY JR., William R. The Population of Florence before the Black Death: Survey and Synthesis. Journal of Medieval History, Amsterdam, n. 28, p. 93-129, 2002.

DE VRIES, Jan. The Industrious Revolution. Cambridge: Cambridge University Press, 2009.

DEVEZAS, Tessaleno; MODELSKI, George; THOMPSON, William. Globalization as Evolutionary Process. Nova York: Routledge, 2008.

EVANS, Allan. Introduction. In: PEGOLOTTI, F. La Pratica della Mercatura. Edited by Allan Evans. New York: Kraus Reprint Co, 1970. p. XV-XXVI.

FIGLIUOLO, Bruno. Tipologia economica della città nel basso Medioevo. Nuova Rivista Storica, Roma, v. 99, p. 823-836, 2015.

FLYNN, Dennis O. Silver in a Global Context, 1400-1800. In: BENTLEY, J.; SUBRAHMANYAM, S.; WIESNER-HANKS, M. (ed.). The Construction of a Global World, 1400-1800. Cambridge: Cambridge University Press, 2015. v. 2, p. 213-239.

FRAENGER, Wilhelm. Hieronymus Bosch: Le tentazioni di Sant'Antonio. Milano: Abscondita SRL, 2007.

FRANK, Andre Gunder; GILLS, Barry K. The 5.000-Year World System. In: FRANK, A. G.; GILLS, B. K. (ed.). The World System. London: Routledge, 1996. p. 3-58.

GREEN, Monica (ed.). Pandemic Disease in the Medieval World: Rethinking the Black Death. Michigan: Arc Humanities Press, 2014.

HERLIHY, David. Pisa in the Early Renaissance. New York: Yale University Press, 1958.

HOSHINO, Hidetoshi. L'arte della Lana in Firenze nel Basso Medioevo. Firenze: Olschki, 1980. 
HUNT, Edwin. The Medieval Super-Companies. Cambridge: Cambridge University Press, 1994.

JACOBY, David. Byzantine trade with Egypt from the mid-tenth century to the Fourth Crusade. In: JACOBY, D. Commercial Exchange across the Mediterranean. Hampshire: Variorum Collected Studies, 2005. p. 25-77.

JORDAN, William C. The Great Famine. New Jersey: Princeton University Press, 1996.

LENZI, Domenico. I/ libro del Biadaiolo. A cura di Giuliano Pinto. Firenze: Leo S. Olschki Editore, 1978.

LIVERANI, Mario. Antico Oriente: storia, società, economia. Bari: Laterza, 2011.

McNEILL, William H. Foreword. In: FRANK, A. G.; GILLS, B. K. (ed.). The World System. London: Routledge, 1996. p. VII-XIII.

MURRAY, James M. Bruges, Cradle of Capitalism. Cambridge: Cambridge University Press, 2006.

NAJEMY, John. A History of Florence (1200-575). Malden: Blackwell Publishing, 2006.

PEGOLOTTI, Francesco. La Pratica della Mercatura. Edited by Allan Evans. New York: Kraus Reprint Co, 1970.

POLANYI, Karl. A grande transformação. Rio de Janeiro: Elsevier, 2000.

RONCIĖRE, Charles de La. Un changeur florentin du Trecento: Lippo di Fede del Sega. Paris: SEVPEN, 1973.

SAHLINS, Marshal. Stone Age Economics. London: Tavistock Publications, 1974.

SCHWARTZ, Frederic J. Ernst Bloch and Wilhelm Pinder: out of Sync. Grey Room, New York, n. 3, p. 54-89, 2001.

STERN, Steve. Los pueblos indígenas del Perú y el desafío de la conquista española. Madrid: Alianza Editorial, 1982.

TOMICH, Dale. A ordem do tempo histórico: a Longue Durée e a Micro-História. Revista Almanack, Guarulhos, n. 2, p. 38-51, 2011.

VILLANI, Giovanni. Nuova Cronica. A cura di Giuseppe Porta. Parma: Einaudi, 1991.

WALLERSTEIN, Immanuel. World System versus World-System. In: FRANK, A. G.; GILLS, B. K. (ed.). The World System. London: Routledge, 1996. p. 292-296. 
WALLERSTEIN, Immanuel. The Modern World-System: capitalist agriculture and the origins of the European world-economy in the sixteenth century. San Diego: Academic Press, 1974.

WALLERSTEIN, Immanuel. The Modern World-System II: Mercantilism and the consolidation of the European World-Economy, 1600-1750. New York: Academic Press, 1980.

WALLERSTEIN, Immanuel. The Modern World-System III: The second Era of great expansion of the Capitalist World-Economy, 1730-1840. New York: Academic Press, 1989.

WALLERSTEIN, Immanuel. The Modern World-System IV: Centrist Liberalism Triumphant, 1789-1914. Berkeley: University of California Press, 2011.

\section{NOTAS}

\section{AUTORIA}

Felipe Mendes Erra: Graduado. Mestrando, Universidade de São Paulo, Faculdade de Filosofia, Letras e Ciências Humanas, Departamento de História, São Paulo, SP, Brasil.

\section{ENDEREÇO PARA CORRESPONDÊNCIA}

Rua São Joaquim, n. 249, Ap. 11, 01508-001, São Paulo, SP, Brasil.

\section{ORIGEM DO ARTIGO}

Este artigo existe em decorrência da pesquisa de mestrado intitulada "O mercado de grãos de Florença (1310-1335)", pertencente ao Programa de Pós-graduação de História Econômica da USP, programada para terminar em 03/2020; às discussões realizadas no Laboratório de Estudos Medievais (núcleo SP); e ao período de estágio como pesquisador visitante no CIHAM - UMR 5648, em Lyon (França).

\section{AGRADECIMENTOS}

Gostaria de agradecer aos professores Marcelo Cândido da Silva, pela desafiadora e produtiva proposição do tema da História Global como agenda de pesquisa, ao professor Jean-Louis Gaulin, pela fraterna recepção em Lyon e pela amplitude de visão oferecida a partir de comentários feitos à investigação em andamento.

\section{FINANCIAMENTO}

Essa pesquisa foi financiada por bolsa de mestrado da Fundação de Amparo à Pesquisa do Estado de São Paulo (FAPESP), processo n. 17/13122-8, e por uma Bolsa de Estágio de Pesquisa no Exterior financiada também pela FAPESP, processo n. 18/19704-1.

\section{APROVAÇÃO DE COMITÊ DE ÉTICA EM PESQUISA}

Não se aplica.

\section{CONFLITO DE INTERESSES}

Não houve conflito de interesses.

\section{LICENÇA DE USO}

Este artigo está licenciado sob a Licença Creative Commons CC-BY. Com essa licença você pode compartilhar, adaptar e criar para qualquer fim, desde que atribua a autoria da obra. 


\section{PUBLISHER}

Universidade Federal de Santa Catarina. Programa de Pós-Graduação em História. Portal de Periódicos UFSC. As ideias expressadas neste artigo são de responsabilidade de seus autores, não representando, necessariamente, a opinião dos editores ou da universidade.

\section{EDITORES}

Alex Degan

Fábio Augusto Morales

Flávia Florentino Varella (Editora-chefe)

\section{HISTÓRICO}

Recebido em: 1 de agosto de 2019

Aprovado em: 16 de dezembro de 2019

Como citar: ERRA, Felipe Mendes. Perspectivas da história econômica global da Baixa Idade Média. Esboços, Florianópolis, v. 27, n. 44, p. 17-37, jan./abr. 2020. 